\title{
TINGKAT KECEMASAN PASIEN GAGAL GINJAL KRONIK DALAM MENJALANI HEMODIALISA DI RUMAH SAKIT IMELDA PEKERJA INDONESIA
}

\author{
Hamonangan Damanik \\ Universitas Imelda Medan, Jl. Bilal No. 52 Kelurahan Pulo Brayan Darat I Kecamatan Medan Timur, \\ Medan - Sumatera Utara. \\ Email : hamonangan1112@gmail.com
}

\begin{abstract}
ABSTRAK
Gagal ginjal kronik merupakan kerusakan ginjal progresif ditandai dengan uremia (urea dan limbah lain yang beredar di dalam darah serta komplikasinya jika tidak di lakukan dialisis atau transplantasi ginjal). Penderita gagal ginjal kronik yang akan melakukan hemodialisa sering mengalami kecemasan. Kecemasan merupakan reaksi normal terhadap situasi yang sangat menekan kehidupan seseorang yang berlangsung tidak lama. Penelitian ini bertujuan untuk mengetahui bagaimana tingkat kecemasan pasien gagal ginjal kronik dalam menjalani hemodialisa di Rumah Sakit Imelda Pekerja Indonesia. Jenis penelitian yang digunakan adalah deskriptif dengan rancangan studi cross sectional. Penelitian dilakukan pada April tahun 2019. Populasi dalam penelitian ini adalah seluruh pasien yang menjalani hemodialisis di RS Imelda Pekerja Indonesia sebanyak 205 orang. Tehnik sampling pada penelitian ini adalah tekhnik nonprobability sampling yaitu purposive sampling dengan demikian jumlah sampel pada penelitian ini sebanyak 31 orang. Hasil penelitian menunjukkan bahwa mayoritas responden yang menjalani hemodialisa mengalami kecemasan dengan tingkat kecemasan sedang 19 orang (61,3\%), sedangkan minoritas responden hemodialisa dengan tingkat kecemasan berat 4 orang (12,9\%).Disarankan bagi responden agar dapat mencari informasi mengenai terapi hemodialisis, seperti manfaat, proses dan dampak yang ditimbulkan oleh terapi tersebut. Dengan demikian responden dapat memahami bahwa terapi yang diberikan adalah untuk membantunya tetap sehat.
\end{abstract}

Kata kunci: Gagal Ginjal Kronis, Kecemasan, Hemodialisa.

\section{ABSTRACT}

Chronic kidney failure is progressive kidney damage characterized by uremia (urea and other wastes that circulate in the blood and its complications if no dialysis or kidney transplantation is performed). Patients with chronic kidney failure who will do hemodialysis often experience anxiety. Anxiety is a normal reaction to situations that greatly suppress a person's life that lasts for a short time. This study aims to determine how the level of anxiety of chronic kidney failure patients undergoing hemodialysis at the Indonesian Worker Imelda Hospital. This type of research is descriptive with cross sectional study design. The study was conducted in April 2019. The population in this study were all patients who underwent hemodialysis at the Indonesian Imelda Workers' Hospital as many as 205 people. The sampling technique in this study is the nonprobability sampling technique that is purposive sampling so the number of samples in this study were 31 people. The results showed that the majority of respondents who underwent hemodialysis experienced anxiety with moderate anxiety levels of 19 people (61.3\%), while the minority of hemodialysis respondents with severe anxiety levels of 4 people (12.9\%). It is recommended for respondents to be able to seek information about therapy hemodialysis, such as the benefits, processes and effects caused by these therapies. Thus the respondent can understand that the therapy given is to help him stay healthy.

Keywords: Chronic Kidney Failure, Anxiety, Hemodialysis.

\section{PENDAHULUAN}

Gagal ginjal kronik merupakan kerusakan ginjal progresif ditandai dengan uremia (urea dan limbah lain yang beredar di dalam darah serta komplikasinya jika tidak di lakukan dialisis atau transplantasi ginjal). Gagal ginjal kronik (GGK) merupakan suatu gejala klinis karena penurunan fungsi ginjal yang bersifat menahun, gagal ginjal juga menyebabkan kematian apabila tidak dilakukan terapi pengganti, karena kegagalan fungsi ginjal untuk mempertahankan metabolisme dan elektrolit. (Muttaqin \& Sari, 2011).

Data di Amerika terdapat sekitar 20 juta orang memiliki kerusakan ginjal (American Nephrology Nurses Asosiation, 2014). Diantaranya 2,35\% mengalami gagal ginjal 
tahap akhir. (Riskesdas, 2015). Penderita gagal ginjal di Indonesia mengalami peningkatan pada tahun 2011 dengan jumlah penderita gagal ginjal kronik sebesar 15.353 kasus dan pada tahun 2014 naik sebesar 17.193. (Infodatin, 2017). Jumlah penderita gagal ginjal di Indonesia akhir-akhir ini cenderung meningkat, diperkirakan setiap 1.000.000 penduduk, 20 orang mengalami gagal ginjal/tahun. Saat ini jumlah penderita gagal ginjal di Indonesia mencapai 4500 orang. Kecenderungan kenaikan penderita gagal ginjal terlihat dari meningkatnya jumlah pasien cuci darah dengan jumlah ratarata 250 orang pertahun. Data penderita menurut Indonesia Renal Regystri tahun (2011) di Indonesia sekitar 15.353 menjalani hemodialisa (Hidayati, 2014).

Penderita gagal ginjal kronik yang akan melakukan hemodialisa sering mengalami kecemasan. Penelitian yang dilakukan oleh Kring et al (2009) menunjukkan bahwa pasien gagal ginjal yang menjalani hemodialisa yang mengalami kecemasan sebanyak $61 \%$ responden. Kecemasan yang dirasakan pasien muncul karena pasien belum mengetahui bagaimana prosedur dan efek samping dari hemodialisa. Perubahan yang dialami oleh pasien gagal ginjal kronik yang mengalami kecemasan menimbulkan perubahan drastis bukan hanya fisik tetapi juga psikologis pada pasien. Kecemasan merupakan reaksi normal terhadap situasi yang sangat menekan kehidupan seseorang yang berlangsung tidak lama. Proses dari hemodialisis menimbulkan stress psikologis (kecemasan) dan fisik yang mengganggu sistem neurologi sebagai contoh kecemasan, diorientasi tremor, penurunan konsentrasi (Smeltzer \& Bare, 2009).

Hemodialisa merupakan salah satu terapi untuk pengganti fungsi ginjal, selain itu terdapat terapi pengganti seperti peritonial dialisa, dan transplantasi ginjal. Hemodialisa merupakan terapi yang berfungsi untuk menggantikan peran ginjal yang beroperasinya menggunakan sebuah ala yangt khusus untuk mengeluarkan toksik uremik dan mengatur cairan elektrolit tindakan ini juga merupakan upaya untuk meningkatkan kualitas hidup penderita gagal ginjal kronik (Infodatin, 2017).

Pasien gagal ginjal kronik mengalami yang kecemasan akan mengalami banyak gangguan dalam perilakunya diantaranya mengalami penurunan dan perubahan dalam memenuhi kebutuhan fisiologis, perubahan respon psikologis, perubahan pada interaksi sosial, penurunan kualitas fisik, fisiologi dan sebagainya. Kecemasan sangat sering dijumpai pada pasien hemodialisa. 57,30\% dari pasien End Stage Renal Disease (ESRD) mengalami depresi. Dari 39,2\% pasien dialisis terdapat pasien yang mengalami depresi ringan, 24,49\% mengalami depresi sedang dan $13,72 \%$ memiliki depresi berat dan $42,69 \%$ yang mengalami gangguan kecemasan dari $47,36 \%$ pasien yang mengalami kecemasan ringan, 28,94\% mengalami kecemasan sedang dan 23,68\% mengalami kecemasan yang parah (Tavir, 2013)

Kecemasan pada pasien hemodialisis dapat terjadi akibat terapi yang berlangsung seumur hidup dan pasien membutuhkan ketergantungan pada mesin yang pelaksanaanya rumit dan membutuhkan waktu yang lama serta memerlukan biaya yang relatif besar. Untuk mengatasi gangguan psikologis tersebut diperlukan dukungan sosial keluarga agar dapat menurunkan efek psikologis yang ditimbulkan (Lumenta, 2016).

Menurut penelitian yang berkaitan dengan gagal ginjal kronik dalam menjalani hemodialisa menyatakan hasil analisa data yang didapat menunjukkan bahwa tidak semua faktor tersebut memiliki hubungan yang signifikan terhadap kualitas hidup pasien GGK (P. Sagala, 2015).

Menurut penelitian yang berjudul "Hubungan Strategi Koping Dengan Kualitas Hidup Pada Pasien Gagal Ginjal Kronik Yang Menjalani Hemodialisadi Rsu Imelda Medan" menyatakan hasil analisis diperoleh nilai correlation coefficient $(r)=0,733$, menunjukkan hubungan yang kuat dan berpola positif artinya semakin tinggi penggunaan strategi Problem Focused Coping (PFC) maka kualitas hidup yang dimiliki pasien gagal ginjal kronis yang menjalani hemodialisa semakin baik, Sedangkan hasil analisis diperoleh nilai correlation coefficient (r) $=-0,419$, menunjukkan hubungan yang sedang dan berpola negatif artinya semakin rendah penggunaan strategi Emotion Focused Coping (EFC) maka kualitas hidup yang 
dimiliki pasien gagal ginjal kronis yang menjalani hemodialisa semakin baik (D. S. P. Sagala \& Pasaribu, 2018).

Penelitian lain yang berkaitan dengan kecemasan pasien yang menjalani hemodialisa menyatakan pengaruh pemberian konseling pada pasien hemodialisis dengan tingkat kecemasan, diperoleh bahwa nilai $\mathrm{p}$ value 0.00 . Diharapkan kepada perawat untuk memberikan edukasi dan konseling kepada pasien hemodialisis yang sedang menjalani hemodialisis agar pasien merasa nyaman dan tidak cemas (Silaen, 2018).

Berdasarkan hal tersebut diatas maka peneliti ingin mengetahui tingkat kecemasan pasien gagal ginjal kronik dalam menjalani hemodialisa di Rumah Sakit Imelda Pekerja Indonesia.

\section{METODE PENELITIAN}

Jenis penelitian yang digunakan adalah deskriptif dengan rancangan studi cross sectional yang bertujuan untuk mengetahui tingkat kecemasan pasien gagal ginjal kronis yang menjalani hemodialisa di Rumah Sakit Imelda Pekerja Indonesia Penelitian ini dilakukan di Rumah Sakit Imelda Pekerja Indonesia yang dilaksanakan pada bulan April 2019.

\section{Populasi}

Populasi dalam penelitian ini adalah seluruh pasien yang menjalani hemodialisis di RS Imelda Pekerja Indonesia sebanyak 205 orang.

\section{Sampel}

Sampel adalah pasien hemodialisis, pengambilan sampel penelitian dilakukan dengan tekhnik Nonprobability sampling yaitu Purposive Sampling. Disini peneliti menggunakan rumus Surakhmat (2009) menyatakan bahwa apabila populasi lebih dari 200, maka besar sampel dapat diambil antara $15-20 \%$, sehubungan dengan populasi penelitian sebesar 205 orang (dikutip dari jumlah pasien yang menjalani hemodialisis tahun 2018 di RS Imelda Pekerja Indonesia) maka besar sampel diambil $15 \%$.

$$
\begin{aligned}
\mathrm{n} & =\mathrm{N} \times 15 \% \\
& =205 \times 15 \% \\
& =30,75
\end{aligned}
$$

Jadi sampel yang diambil sebanyak 31 orang dan yang memenuhi kriteria sebagai berikut :
1. Pasien yang akan menjalani hemodialisis

2. Dapat menulis, membaca dan berkomunikasi dengan bahasa Indonesia.

3. Bersedia menjadi responden.

\section{Metode Pengumpulan Data}

Metode pengumpulan data yang dilakukan peneliti adalah dengan cara responden diberikan angket atau kuesioner. Peneliti menjelaskan kepada calon responden tentang tujuan, manfaat, dan prosedur pengisian kuesioner. Calon responden yang bersedia diminta untuk menandatangani lembar persetujuan yang telah disediakan. Responden dipersilahkan untuk menjawab semua pernyataan yang diajukan peneliti dalam kuesioner dan diberi waktu lebih kurang 15 menit serta diberikan kesempatan untuk bertanya kepada peneliti bila ada yang tidak mengerti atau kurang jelas.

\section{Definisi Operasional}

Kecemasan merupakan perasaan tidak nyaman seperti gelisah, takut atau khawatir yang dirasakan pasien selama prosedur hemodialisis berlangsung di ruang hemodialisa RS Imelda Pekerja Indonesia.

\section{Aspek Pengukuran}

Untuk mengetahui tingkat kecemasan yang dialami pasien diukur dengan 10 pertanyaan dan dengan option pilihan ya diberi skor 1, dan tidak diberi skor 0. Skor yang tertinggi yang dinilai dari responden untuk tingkat kecemasan adalah 10 dan nilai terendah adalah 0 . Berdasarkan rumus statistik:

$P=\underline{\text { Rentang }}$

Banyak kelas

$$
\begin{aligned}
& =\frac{10-0}{3} \\
& =3,3 \text { atau } 3
\end{aligned}
$$

Diamana $\mathrm{p}$ merupakan panjang kelas dengan rentang nilai tertinggi di kurangi nilai terendah, banyak kelas 3 kategori yaitu ringan, sedang, berat, sehingga panjang kelas adalah sebanyak 3 kelas. Berikut adalah pengkategorian hasil skoring terhadap tingkat kecemasan yaitu cemas ringan (0-3), cemas sedang (4-6), cemas berat (7-10).

\section{Analisa Data}

Analisa univariat untuk mengetahui distribusi frekuensi, dan persentase dari 
variabel yang diteliti yaitu tentang tingkat kecemasan.

HASIL

Karakteristik Responden

Tabel 1. Distribusi Frekuensi karakteristik Responden hemodialisa di RS IPI tahun 2019

\begin{tabular}{|c|c|c|c|}
\hline No & Karakteristik & $\mathbf{n}$ & $\%$ \\
\hline \multirow[t]{4}{*}{1} & Umur & & \\
\hline & $<45$ & 4 & 12,9 \\
\hline & $46-56$ & 7 & 22,6 \\
\hline & $>57$ & 20 & 64,5 \\
\hline \multirow[t]{3}{*}{2} & Jenis Kelamin & & \\
\hline & Laki-laki & 20 & 64,5 \\
\hline & Perempuan & 11 & 35,5 \\
\hline \multirow[t]{6}{*}{3} & Agama & & \\
\hline & Islam & 13 & 41,9 \\
\hline & Kristen Protestan & 18 & 58,1 \\
\hline & Katolik & 0 & 0 \\
\hline & Budha & 0 & 0 \\
\hline & Hindu & 0 & 0 \\
\hline \multirow[t]{6}{*}{4} & Pekerjaan & & \\
\hline & Pegawai Negeri & 9 & 29,0 \\
\hline & Pegawai Swasta & 4 & 12,9 \\
\hline & Pedagang/Wiraswasta & 11 & 35,5 \\
\hline & Petani & 7 & 22,6 \\
\hline & Jumlah & 31 & 100 \\
\hline
\end{tabular}

Dari tabel diatas dapat dilihat bahwa mayoritas umur responden hemodialisa > 57 tahun 20 orang $(64,5 \%)$, mayoritas jenis kelamin responden hemodialisa laki 20 orang (64,5\%), mayoritas agama responden hemodialisa Kristen 18 orang $(58,1 \%)$, Mayoritas pekerjaan responden hemodialisa sebagai wiraswasta 11 orang $(35,5 \%)$.

\section{Tingkat Kecemasan Pasien Hemodialisa}

Tabel 2. Distribusi Frekuensi Tingkat kecemasan Pasien Hemodialisa di RS IPI tahun 2019

\begin{tabular}{cccc}
\hline No & $\begin{array}{c}\text { Tingkat } \\
\text { Kecemasan Pasien }\end{array}$ & $\begin{array}{c}\text { Frekuensi } \\
(\mathbf{F})\end{array}$ & Persentase \\
\hline 1 & Cemas ringan & 8 & 25,8 \\
2 & Cemas sedang & 19 & 61,3 \\
3 & Cemas berat & 4 & 12,9 \\
\hline & Jumlah & 31 & 100 \\
\hline
\end{tabular}

Dari tabel diatas dapat dilihat bahwa mayoritas responden yang menjalani hemodialisa mengalami kecemasan dengan tingkat kecemasan sedang 19 orang $(61,3 \%)$, sedangkan minoritas responden hemodialisa dengan tingkat kecemasan berat 4 orang $(12,9 \%)$.

\section{PEMBAHASAN}

Setelah melakukan penelitian di RS IPI dengan jumlah responden sebanyak 31 orang melalui penyebaran kuesioner yang berisikan tingkat kecemasan maka diperoleh hasil yaitu mayoritas responden dengan tingkat kecemasan sedang 19 orang $(61,3 \%)$, sedangkan minoritas dengan tingkat kecemasan berat 4 orang (12,9\%).

Kecemasan merupakan hal yang sering terjadi dalam hidup manusia tertutama pada penderita penyakit kronis. Klien yang dirawat karena penyakit yang mengancam kehidupan akan lebih sering mengalami kecemasan, depresi atau marah (Stuart, 2009). Keadaan tersebut menyebabkan kehidupan individu tersebut selalu di bawah bayang-bayang kecemasan yang berkepanjangan dan menganggap rasa cemas sebagai ketegangan mental.

Kecemasan berhubungan dengan stress fisiologis maupun psikologis, artinya cemas terjadi ketika seseorang terancam baik secara fisik maupun psikologis. Secara fisik klien terlihat gelisah, gugup dan tidak dapat duduk atau istirahat dengan tenang (Hawari, 2011). Dari hasil penelitian diatas pada tabel 4.2 yaitu mayoritas responden mengalami kecemasan dengan tingkat kecemasan sedang 19 orang (61,3\%), sedangkan minoritas responden dengan tingkat kecemasan berat 4 orang $(12,9 \%)$.

Hasil penelitian ini sesuai dengan Tanvir (2013) yang menunjukkan sebagian besar pasien gagal ginjal kronik yang menjalani hemodialisis mengalami tingkat kecemasan sedang. Seseorang menderita gangguan kecemasan ketika orang tersebut tidak mampu mengatasi stressor yang sedang dihadapinya. Keadaan seperti ini secara klinis bisa terjadi menyeluruh dan menetap dan paling sedikit berlangsung selama 1 bulan.

Tingkat kecemasan yang sedang dapat dipengaruhi oleh faktor jenis kelamin responden yang sebagian besar laki-laki $(64,5 \%)$. Laki-laki bersifat lebih kuat secara fisik dan mental, laki-laki dapat dengan mudah mengatasi sebuah stressor oleh karena itu laki-laki lebih rileks dalam menghadapi sebuah masalah, sedangkan perempuan memiliki sifat lebih sensitive dan sulit menghadapi sebuah stressor sehingga perempuan lebih mudah merasa cemas dan takut dalam berbagai hal misalnya seperti dalam menghadapi kenyataan bahwa harus menjalani pengobatan secara terus menerus untuk kelangsungan hidupnya. 
Hal ini diperkuat oleh Halgin (2012) gangguan kecemasan umumnya mempengaruhi $8,3 \%$ dari populasi dan biasanya terjadi pada wanita. Hal ini didukung oleh penelitian Widiyati (2016) yang menyimpulkan ada hubungan antara jenis kelamin dengan kecemasan pasien gagal ginjal kronik yang menjalani hemodialisa.

Faktor lain yang bisa mempengaruhi tingkat kecemasan adalah usia responden yang sebagian besar masuk pada kelompok usia lansia akhir (64,5\%). Menurut Isaac dalam Untari (2014) seseorang yang mempunyai usia lebih muda ternyata lebih mudah mengalami gangguan kecemasan daripada seseorang yang lebih tua. Pada usia dewasa seseorang sudah memiliki kematangan baik fisik maupun mental dan pengalaman yang lebih dalam memecahkan masalah sehingga mampu menekan kecemasan yang dirasakan. Semakin tua umur seseorang akan terjadi proses penurunan kemampuan fungsi organ tubuh (regenerative) hal ini akan mempengaruhi dalam mengambil keputusan terutama dalam menangani penyakit gagal ginjal kronik dengan terapi hemodialisis.

Pada usia tua seseorang dapat menerima segala penyakitnya dengan mudah karena di usia tua seseorang cenderung berfikir bahwa secara spiritual tua harus dijalani dan dihadapi sebagai salah satu hilangnya nikmat sehat secara perlahan. Hal ini didukung oleh penelitian Julianti, Yustina \& Ardinata (2015) yang menunjukkan adanya hubungan antara usia dengan tingkat kecemasan pasien gagal ginjal kronik yang menjalani hemodialisa di Rumah Sakit Umum Daerah Dr. Pirngadi Medan.

Disamping faktor-faktor di atas pekerjaan responden yang sebagian besar wiraswasta $(35,5 \%)$ juga merupakan faktor lain yang dapat mempengaruhi tingkat kecemasan responden. Pekerjaan berkaitan dengan status ekonomi seseorang. Seseorang dengan status sosioekonomi yang lebih rendah memiliki risiko yang lebih besar dibandingkan dengan mereka dengan status sosioekonomi yang lebih baik. Hal ini dikarenakan seseorang dengan status ekonomi yang lebih rendah akan menyebabkan kebutuhan gizi yang kurang sehingga mudah terkena depresi (Santoso \& Ismail, 2009).

\section{KESIMPULAN}

Berdasarkan hasil penelitian mengenai tingkat kecemasan pasien gagal ginjal kronis yang menjalani hemodilisis di RS IPI Medan dapat disimpulkan bahwa:

1. Berdasarkan karakteristik bahwa mayoritas umur responden hemodialisa > 57 tahun 20 orang $(64,5 \%)$, mayoritas jenis kelamin responden hemodialisa laki 20 orang $(64,5 \%)$, mayoritas agama responden hemodialisa kristen 18 orang $(58,1 \%)$, mayoritas pekerjaan responden hemodialisa sebagai wiraswasta 11 orang $(35,5 \%)$.

2. Berdasarkan tingkat kecemasan bahwa mayoritas responden hemodialisa dengan tingkat kecemasan sedang 19 orang $(61,3 \%)$, sedangkan minoritas responden hemodialisa dengan tingkat kecemasan berat 4 orang $(12,9 \%)$.

\section{DAFTAR PUSTAKA}

Badan penelitian \& pengembangan kesehatan RI. (2013). Laporan hasil riset kesehatan dasar (Riskesdas) tahun 2015 Kementrian Kesehatan Republik Indonesia. Jakarta.

Burn \& Davidson. (2014). Terapi Kognitif untuk Depresi dan Kecemasan Suatu Petunjuk bagi Praktisi, Cetakan I, Penerbit IKIP Semarang Press. Semarang.

Corwin, J. E. (2010). Buku Saku Patofisiologi. EGC. Bandung.

Friedman, M. M. (2009). Keperawatan Keluarga: Teori dan Praktik. Edisi III. Penerbit EGC. Jakarta.

Halgin. R. P. (2012), Psikologi Abnormal. Edisi 6, Salemba Humanika. Jakarta

Hawari, D. (2011). Manajemen Sres, Cemas dan Depresi. Cetakan II FKUI Jakarta

Hidayati. Y.S.D. (2014). Penderita Gagal Ginjal Meningkat. Dibuka pada website http://www.

Tempo.co.id/medika/arsip/022002/keg1.htm. diakses 14 April 2019.

Hudak \& Gallo. (2011). Keperawatan Kritis Pendekatan Holistik. Volume II, Edisi VI, Cetakan I, Penerbit EGC. Jakarta.

Infodatin pusat data dan informasi kementerian kesehatan RI. CKD. (2017) Kementerian kesehatan RI. Jakarta.

Julianty. S.A, Yustina. I \& Ardinata. D. (2015), Faktor-Faktor Yang Berhubungan Dengan Tingkat 
Kecemasan Pasien Hemodialisis Di RSUD Dr. Pirngadi Medan, Idea Nursing Journal, ISSN: 20872879.http://jurnal.unsyiah.ac.id/INJ/artic le/viewFile/6736/5520 di akses pada 20 April 2019.

Kring, et al. (2009), A Rating Instrument For Anxiety Disorders, Official Journal of The Academy of Psychosomatic Medicine, 12 (6), Page 371379.http://www.psychosomaticsjournal. com/article/S00333182(71)714790/abstract, diakses pada 18 April 2019.

Lumenta, N.A, dkk. (2016). Penyakit Ginjal, penyebab, Pengobatan Medik dan Pencegahanya. Cetakan I. Penerbit PT. BPK Gunung Mulia. Jakarta.

Mansjoer A, dkk. (2009). Kapita Selekta Kedokteran. Edisi III. Penerbit Media Aesculapius. Jakarta.

Muttaqin, Arif \& sari, Kumala. (2011). Gangguan gastrointestinal : aplikasi

asuuhan keperawatan medical bedah. Salemba Medika. Jakarta.

Santoso. H. (2009), Memahami Krisis Lanjut Usia, Jakarta, Gunung Mulia.

Smaltzer, Suzane C. and Bare. (2009). Buku ajar keperawatan medical bedah. Vomule 2, edisi 8. EGC. Jakarta.

Stuart \& Sudden. (2010). Keperawatan Medikal Bedah, Edisi 8. EGC. Jakarta.

Sagala, D. S. P., \& Pasaribu, S. M. (2018). HUBUNGAN STRATEGI KOPING DENGAN KUALITAS HIDUP PADA PASIEN GAGAL GINJAL KRONIK YANG MENJALANI HEMODIALISADI RSU IMELDA MEDAN. Jurnal Ilmiah Keperawatan Imelda, 4(2), 84-93. http://jurnal.uimedan.ac.id/index.php/JU RNALKEPERAWATAN/article/view/2 $89 / 292$

Sagala, P. (2015). Analisa Faktor-Faktor Yang Mempengaruhi Kualitas Hidup Pasien Gagal Ginjal Kronik Yang Menjalani Hemodialisa Di Rumah Sakit
Umum Pusat Haji Adam Malik Medan. Jurnal Ilmiah Keperawatan IMELDA, 1(1), 8-16.

Silaen, H. (2018). PENGARUH PEMBERIAN KONSELING DENGAN TINGKAT KECEMASAN PADA PASIEN YANG MENJALANI HEMODIALISIS DI RUMAH SAKIT KOTA MEDAN. Jurnal Ilmiah Keperawatan Imelda, 4(1), 52-57. http://jurnal.uimedan.ac.id/index.php/JU RNALKEPERAWATAN/article/view/2 $84 / 287$

Tanvir. S, But. G. D, Taj. R. (2013), Prevalence Of Depression And Anxiety In Chronic Kidney Disease Patients On Haemodialysis, Ann Pakistan Institusee of Medical Sciences, 9 (2).http://apims.net/apims_old/Volumes/ Vol9,2/Prevalence\%20of\%20Depressio n\%20and\%20Anxiety\%20in\%20Chroni c\%20Kidney\%20Disease.pdf, diakses pada 20 April 2019.

Tjokronegoro. (2011). Buku Ajar Ilmu Penyakit Dalam. Edisi 3. FKUI. Jakarta.

Untari. I \& Rohmawati. (2014), FaktorFaktor Yang Mempengaruhi Kecemasan Pada Usia Pertengahan Dalam Menghadapi Proses Menua (Aging Prosess), Jurnal Keperawatan Akper 17 Karanganyer, (2).http://jurnal.akper17.ac.id/index.php/ JK17/article/view/9 di akses pada 23 April 2019.

Widiyati. S. (2016), Hbungan Mekanisme Koping Individu Dengan Tingkat Kecemasan Pada Pasien Gagal Ginjal Kronik Yang Menjalani Hemodialisa Di Bangsal Teratai RSUD dr. Soedirman Mangun, Naskah Publikasi, StiKes Kusuma Husada Surakarta. http://digilib.stikeskusumahusada.ac.id/f iles/disk1/30/01-gdsriwidiyat-1483-1artikel-0.pdf di akses pada 20 April 2019. 